\title{
Use of Psychoactive Medication and the Quality of Care in Rest Homes
}

\section{Citation}

Avorn, Jerry, Paul Dreyer, Kathleen Connelly, and Stephen B. Soumerai. 1989. "Use of Psychoactive Medication and the Quality of Care in Rest Homes." New England Journal of Medicine 320 (4) (January 26): 227-232. doi:10.1056/nejm198901263200406.

\section{Published Version}

doi:10.1056/NEJM198901263200406

\section{Permanent link}

http://nrs.harvard.edu/urn-3:HUL.InstRepos:32692040

\section{Terms of Use}

This article was downloaded from Harvard University's DASH repository, and is made available under the terms and conditions applicable to Other Posted Material, as set forth at http:// nrs.harvard.edu/urn-3:HUL.InstRepos:dash.current.terms-of-use\#LAA

\section{Share Your Story}

The Harvard community has made this article openly available.

Please share how this access benefits you. Submit a story.

\section{Accessibility}


50. Adson AW, Coffey JR. Cervical rib: a method of anterior approach for relief of symptoms by division of the scalenus anticus. Ann Surg 1927; 85: 839-57.

51. Roos DB. Congenital anomalies associated with thoracic outlet syndrome: anatomy, symptoms, diagnosis, and treatment. Am J Surg 1976; 132:771-8.

52. Costigan DA, Wilbourn AJ. The elevated arm stress test: specificity in the diagnosis of thoracic outlet syndrome. Neurology 1985; 35:Suppl 1:74-5. abstract.

53. Peet RM, Henriksen JD, Anderson TP, Martin GM. Thoracic-outlet syndrome: evaluation of a therapeutic exercise program. Mayo Clin Proc 1956; 31:281-7.

54. Dale WA. Management of vascular surgical problems. New York: McGrawHill, 1985:562-87.

55. Fahn S, Marsden CD, Calne DB. Classification and investigation of dystonia. In: Marsden CD, Fahn S, eds. Movement disorders. 2nd ed. London: Butterworths, 1987:332-58.

56. Cohen LG, Hallett $M$. Hand cramps: clinical features and electromyographic patterns in a focal dystonia. Neurology $1988 ; 38: 1005-12$

57. Marsden CD, Rothwell JC. The physiology of idiopathic dystonia. Can J Neurol Sci 1987; 14:Suppl 3:521-7.

58. Newmark J, Hochberg FH. Isolated painless manual incoordination in $\mathbf{5 7}$ musicians. J Neurol Neurosurg Psychiatry 1987; 50:291-5.

59. Lederman RJ. Occupational cramp in instrumental musicians. Med Probl Perform Art 1988; 3:45-51.

60. Burton K, Farrell H, Li I, Calne DB. Lesions of the putamen and dystonia: CT and magnetic resonance imaging. Neurology $1984 ; 34: 962-5$.
61. Narbona J, Obeso JA, Tunon T, Martinez-Lage JM, Marsden CD. Hemidystonia secondary to localised basal ganglia tumour. J Neurol Neurosurg Psychiatry 1984; 47:704-9.

62. Schott GD. Induction of involuntary movements by peripheral trauma: an analogy with causalgia. Lancet 1986; 2:712-6.

63. Marsden CD, Obeso JA, Traub MM, Rothwell JC, Kranz H, La Cruz F. Muscle spasms associated with Sudeck's atrophy after injury. Br Med J $1984 ; 288: 173-6$

64. Fahn S, Marsden CD. The treatment of dystonia. In: Marsden CD, Fahn S, eds. Movement disorders. 2nd ed. London: Butterworths, 1987: 359-82.

65. Cohen L, Hallett $M$, Geller B, et al. Treatment of focal dystonias of the hand with botulinum toxin injection. Neurology 1987; 37:Suppl 1:123-4.

66. Travers RMW. Essentials of learning. 3rd ed. New York: Macmillan, 1972:204-5.

67. Brandfonbrener AG. The price of perfection. Med Probl Perform Art 1988; 3(1).

68. Tyrer PJ, Lader MH. Response to propranolol and diazepam in somatic and psychic anxiety. Br Med J 1974:2:14-6.

69. Brantigan CO, Brantigan TA, Joseph N. Effect of beta blockade and beta stimulation on stage fright. Am J Med 1982; 72:88-94.

70. James I, Savage I. Beneficial effect of nadolol on anxiety-induced disturbances of performance in musicians: a comparison with diazepam and placebo. Am Heart J 1984; 108:1150-5.

71. Harman SE. Bibliography for occupational diseases in instrumental musicians. Med Probl Perform Art 1987; 2:155-62.

\title{
USE OF PSYCHOACTIVE MEDICATION AND THE QUALITY OF CARE IN REST HOMES
}

\section{Findings and Policy Implications of a Statewide Study}

\author{
Jerry Avorn, M.D., Paul Dreyer, Ph.D., Kathleen Connelly, M.A., and Stephen B. Soumerai, Sc.D.
}

Abstract Rest homes have become a major component of the health care system for frail elderly persons and deinstitutionalized psychiatric patients. Although psychoactive medications are frequently used in rest homes, there is little detailed information about the extent of such use, its supervision, or its effects.

In a survey of a random sample of 55 rest homes in Massachusetts, we found that 55 percent of the residents were taking at least one psychoactive medication. Antipsychotic medications were being administered to 39 percent; of these, 18 percent were receiving two or more such drugs.

In a follow-up investigation, we studied 837 residents in 44 rest homes with particularly high levels of antipsychotic-drug use. About half the residents had no evi-

$\mathrm{T}$ HE growing proportion of frail elderly persons in the population and the movement to deinstitutionalize chronically mentally ill patients from large state hospitals have produced important changes in the character of facilities providing long-term care. Rest homes have traditionally provided only minimal assistance and supervision for relatively independent elderly residents, rather than the nursing, medical, and rehabilitative care provided in nursing homes. Yet in many states, deinstitutionalized psychiatric patients and frail elderly patients are increasingly cared for in these facilities (also known as board-and-care homes, group homes, or domiciliary care facilities).

From the Program for the Analysis of Clinical Strategies, the Division on Aging, and the Department of Social Medicine and Health Policy, Harvard Medical School, and the Beth Israel Hospital (J.A., S.B.S.), and the Massachusetts Department of Public Health, Division of Health Care Quality (P.D., K.C.) Boston. Address reprint requests to Dr. Avorn at the Program for the Analysis of Clinical Strategies, Harvard Medical School, 643 Huntington Ave., Boston, MA 02115. Supported in part by a grant from the John A. Hartford Foundation. dence of participation by a physician in decisions about their mental health during the year of the study. A third of the residents had performance deficits on mental-status testing that indicated serious cognitive impairment, although the causal relation of such impairment to medication use could not be determined. Six percent had evidence of moderate or severe tardive dyskinesia, probably as a side effect of medication. An assessment of staff competence revealed a low level of comprehension of the purpose and side effects of commonly used psychoactive drugs.

We conclude that psychoactive drugs are widely used in rest homes, with little medical supervision or understanding by staff members of their possible side effects. (N Engl J Med 1989; 320:227-32.)

From 1955 to 1980 , the census of state mental hospitals declined 75 percent nationwide, from 559,000 patients to 138,000 patients. Facilities providing longterm care have played a large part in providing ongoing care to these patients. In a single four-year period between 1969 and 1973, the nursing home population 65 years of age or older with chronic mental disorders more than doubled, whereas the number of residents in this age group in psychiatric facilities fell by 30 to 40 percent. ${ }^{1}$ In Massachusetts, the deinstitutionalization program has progressed further than in almost any other state. The state hospital population has declined from 23,000 in 1959 to about 2700 patients currently. Ninety percent of the former state mental hospital patients are now in alternative settings. $^{2}$

Rest home residents compose a relatively small proportion of all patients receiving long-term care. In 1984 , there were 42,000 nursing home patients and 
6100 rest home residents in Massachusetts, and a survey by the Department of Public Health found that 4 percent of nursing home residents and 25 percent of rest home residents (1763 and 1533 patients, respectively) had been admitted from mental hospitals. The appropriateness of nursing home or rest home placements for such patients has often been debated. ${ }^{3,4}$ Nursing home and especially rest home personnel are seldom trained in the special needs of mentally ill clients, ${ }^{1}$ and the heavy use of psychotropic medication in such settings has been questioned. ${ }^{5}$

We have recently reported on the high levels of psychoactive-drug use in intermediate care facilities. ${ }^{6}$ In contrast to the nursing home setting, there are almost no published data for rest homes on the patterns of medication use, the staff's level of knowledge or training in monitoring the effects of powerful psychotropic drugs, or the appropriateness of decisions by physicians to initiate or modify such treatment. A 1971 survey of pharmacy services in 68 rest homes in North Carolina indicated that 69 percent of the personnel who handled medication had no formal training in nursing practices, less than 30 percent of the homes had any drug reference material on hand, and two thirds of the facilities lacked drug-administration records. ${ }^{7}$ A 1980 study $^{8}$ that surveyed the use of antipsychotic drugs among 500 former mental patients randomly selected from California sheltered-care homes found that 76 percent of the residents were taking antipsychotic drugs. Of these, more than one third were taking two or more such drugs concurrently. Two fifths lacked medical supervision and had lower levels of social functioning than supervised residents - particularly older people receiving high doses of antipsychotic agents. High frequencies of adverse drug reactions have been reported among residents of rest homes on admission to a geriatric ward. ${ }^{9}$

Rest homes are typically required by state regulations to provide little more than protective supervision and are usually free from federal regulation because they do not participate in the Medicaid or Medicare programs. In Massachusetts, for example, rest homes are not required to provide more than four hours of consultation by a licensed nurse per 40 -bed unit per month. Physical examinations are required on admission, and reexaminations are required at six-month intervals. Most residents have the costs of their care reimbursed through the Supplemental Security Income program for the disabled, either with (31 percent) or without (29 percent) a supplement provided by the state welfare department. A third of the residents pay their own expenses.

These facilities have been of particular concern to the Massachusetts Department of Public Health because of the changing pattern of responsibilities of the facilities and because of questions of inappropriate use of psychotropic medications, with minimal monitoring by physicians or other health professionals. Optimal management of the complicated clinical problems and potentially dangerous medications associated with major psychiatric disease or chronic illness of all kinds in the elderly requires close surveillance and interaction with medically trained personnel. In Massachusetts, routine licensure inspections by the Department of Public Health have uncovered numerous problems in the care of deinstitutionalized patients, and many serious problems with enforcement have arisen in rest homes with large numbers of such patients. Although current regulations require referring institutions to provide care after deinstitutionalization, such care has in fact been lacking.

In response to such problems, the department initiated a study of the care requirements of rest home residents to determine the nature and extent of psychoactive-drug use and to identify other problems in the delivery of services to residents. The study included (1) a statewide survey of a sample of homes to define the patient population and evaluate the adequacy of placement and patterns of medication use and (2) an intensive review of a subset of these facilities, including an inspection of patients' medication profiles and clinical documentation, an assessment of individual patients' functional status through surveyor-administered standardized tests designed to measure clinical status, and an evaluation of a sample of rest home staff members through the administration of a brief, simple quiz to estimate their capacity to recognize important medication-related problems and to use good judgment in administering these medications.

\section{Methods}

At the time of the initial statewide survey, Massachusetts licensed about 224 free-standing rest homes and 41 rest home units as part of multilevel nursing homes. These facilities cared for approximately 7700 residents. The state also licensed an additional 480 nursing homes containing no rest home beds. The first phase of the study involved the stratified random sampling ${ }^{10}$ of 50 free-standing rest homes and the selection of 5 additional rest homes from the multilevel facilities. The sample was stratified according to the size and geographic location of the facility and the anticipated characteristics of the resident population.

\section{Content of the Statewide Survey}

Data were collected on all residents in the sampled facilities. This sampling scheme resulted in the review of the status and medication regimens of 1201 residents. Data were collected on their demographic characteristics, ability to perform activities of daily living, and medication use and on the frequency of behavioral problems. The frequency of behavioral problems was assessed according to scales developed by the staff of the Department of Mental Health; such problems ranged in seriousness from wandering, severely withdrawn behavior, or verbal abusiveness to fire setting or homicidal behavior. Initially, the demographic information was supplied by the staff of the facility. Clinical staff from the Department of Public Health, Division of Health Care Quality, then visited each facility and obtained the balance of the information by means of record reviews, interviews with staff, and interviews with residents.

\section{The Follow-up Survey}

In this second phase, a more detailed investigation was carried out with use of a subsample of all rest homes in which more than 50 percent of the residents had been admitted from psychiatric facili- 
ties. Homes were also included in the follow-up survey if the proportion of residents who were prescribed antipsychotic medications (neuroleptics) greatly exceeded the proportion of residents admitted from psychiatric hospitals. Data were collected in this component of the study on 837 residents in 44 facilities. Three areas were addressed: medication use, residents' clinical status, and staff members' knowledge.

\section{Medication-Record Review}

Surveyors documented the details and duration of medication use for residents receiving antipsychotic medication. This review included the collection of data on the current regimens of all psychoactive medications, including dosage and details of orders specifying medications to be taken as needed, and a review of the resident's history of using such medications, with particular attention paid to evidence of involvement by physicians in the renewal of orders or the reassessment of a patient's status. The chart-review component of the study was also designed to determine whether adequate records were kept on the clinical status of patients taking antipsychotic medications and to assess procedures to monitor clinical status and to consult with outside health professionals.

\section{Assessment of Individual Residents}

In this part of the study, surveyors from the Department of Public Health administered a standardized test for the assessment of mental status - the Folstein Mini-Mental State Examination, a well-studied instrument that includes tests of orientation, attention, alertness, memory, language, and psychomotor performance. ${ }^{11}$ The surveyors also administered to residents the Abnormal Involuntary Movement Scale test, a standardized instrument designed to evaluate the presence and severity of tardive dyskinesia. ${ }^{12}$

\section{Assessment of Staff Competence}

Since current regulations impose minimal hiring requirements for the staff in rest homes, we sought to determine whether even the most rudimentary lower limit of competence existed in relation to clinical care. Most medications are administered by rest home staff members, for whom training or competence is not required in any area related to such activities. In this phase of the project, surveyors from the Department of Health presented brief, simple clinical vignettes to the staff members responsible for direct patient care. The questions were designed to test basic levels of understanding that would be important for personnel administering such medications. The test was administered to all staff members with patient care responsibilities who were present at the time of the survey, and it dealt with their capacity to recognize important side effects of drugs. The following are sample questions:

Mr. James Smith is a 60 -year-old man admitted to your rest home after being in a state mental hospital for several years. He is taking thioridazine (Mellaril) for his mental problems, digoxin (Lanoxin) for his heart condition, and a diuretic (hydrochlorothiazide [HydroDIURIL]) for high blood pressure. You notice that he is making strange movements of his lips and tongue over and over again. What is the most likely cause of this? (Check only one answer.) (A) He wants more attention; (B) it is related to his heart condition; (C) this is a symptom of being mentally ill; (D) it is a side effect of his Mellaril; (E) his blood pressure is out of control; or $(F)$ he is having a stroke.

Betty Jones is a 75-year-old woman taking several medications. Over several weeks, she seems to be "slowing down" in her movements, getting stiff in her muscles, and she develops a tremor (shake) in her hands. Which medication is the likeliest cause of this, if any? (Check one.) (A) Digoxin; (B) chlordiazepoxide (Librium); (C) haloperidol (Haldol); (D) penicillin; or (E) this cannot be caused by medication.

What effect, if any, does Thorazine (chlorpromazine) have on blood pressure? (Check one.) (A) Thorazine can raise blood pressure, leading to headache or stroke; (B) Thorazine can lower blood pressure, leading to lightheadedness or fainting; or (C) Thorazine does not have any effect on blood pressure.

\section{Results}

\section{The Statewide Sample}

\section{Demographics}

Half the residents in the initial statewide sample of 1201 were 75 years of age or older, and 26 percent were 85 or older. Two thirds were women, and a large proportion of all residents ( 45 percent) had never been married; an additional 38 percent were widows or widowers. A third had a history of psychiatric hospitalization; most of these residents had been admitted to the rest home directly from a state psychiatric hospital. The median length of stay was three years; one fifth had been residents for nine or more years. Data on residents stratified according to the setting from which they were admitted (source of admission) are presented in Table 1. Fewer than 3 percent of the residents were judged by care givers to be physically dangerous to themselves or others, whereas 19 percent of the residents were reported to have engaged in psychotic behavior at least once a year. Twelve percent had engaged in "problem" behavior such as wandering or verbal abusiveness at least once a year.

\section{Medication Use}

In the statewide sample of rest home residents, 39 percent were taking antipsychotic medications (acetophenazine, chlorpromazine, fluphenazine, haloperidol, loxapine, mesoridazine, molindone, perphenazine, prochlorperazine, promethazine, thioridazine, thiothixene, or trifluoperazine); 9 percent, antidepressants; 8 percent, minor tranquilizers; and 3 percent lithium. In most cases, the prescriptions had been written in the remote past and were refilled automatically. Almost all these drugs were given orally by staff members, usually on a daily basis. Fifty-five percent of the residents were taking at least one psychoactive medication, and 11 percent received medications from two or more drug categories.

Although most were taking only one agent from a

Table 1. Characteristics of 1201 Rest Home Patients in a Statewide Sample.

\begin{tabular}{|c|c|c|}
\hline Characteristic & $\begin{array}{l}\text { RESIDENTS ADMITTED } \\
\text { FROM PSYCHIATRIC } \\
\text { HOSPITALS } \\
(\mathrm{N}=\mathbf{3 6 0})\end{array}$ & $\begin{array}{c}\text { ALL OTHER } \\
\text { RESIDENTS } \\
(\mathrm{N}=841)\end{array}$ \\
\hline & \multicolumn{2}{|c|}{ percent } \\
\hline Frequency in sample & 30 & 70 \\
\hline Age (yr) & & \\
\hline $\begin{array}{l}<65 \\
\geqslant 85\end{array}$ & $\begin{array}{r}50 \\
3\end{array}$ & $\begin{array}{l}21 \\
31\end{array}$ \\
\hline Taking neuroleptic medication & 70 & 24 \\
\hline Male & 41 & 25 \\
\hline Source of payment & & \\
\hline Personal funds & 5 & 35 \\
\hline Supplemental Security Income & 79 & 46 \\
\hline Life-care contract & 0 & 11 \\
\hline
\end{tabular}


given therapeutic class, 18 percent of the residents in the statewide sample who were taking antipsychotic medications were receiving two or more different medications in this class. Multiple prescriptions for the other psychotropic medications occurred less frequently: 6 percent of the residents who were receiving antidepressants, 8 percent of those who were taking tranquilizers, and 7 percent of those who were taking lithium received two or more prescriptions for medications within the same class. The use of antipsychotic medications was markedly higher in free-standing homes (4l percent of patients) than in those that were part of multilevel nursing homes (12 percent).

\section{Characteristics of Deinstitutionalized Residents}

In keeping with the effects of deinstitutionalization, residents admitted from psychiatric facilities were much younger than those admitted from other settings (e.g., private residences, acute care hospitals, and other rest homes or nursing homes). Half the residents in the statewide sample who had been admitted from psychiatric hospitals were less than 65 years of age, whereas only 21 percent of those admitted from other settings were this young $(P<0.001)$. The converse was seen for the very old: only 3 percent of the patients from psychiatric hospitals were 85 years of age or older, whereas 31 percent of the residents admitted from other settings were in this age range. As expected, residents admitted from psychiatric facilities were much likelier than other residents to be taking antipsychotic medications ( 70 vs. 24 percent; $\mathbf{P}<0.0001$ ).

Rest homes were not homogeneous in their case mix with respect to psychiatric illness: patients with histories of hospitalization for mental illness were clustered in a few facilities. Twenty-one of the sampled facilities had no such residents, whereas in 13 ( 25 percent) more than half the residents had been patients in a state mental hospital.

\section{The Follow-up Study}

\section{Patient Characteristics}

In this phase of the study, which focused on residents of rest homes with a high frequency of psychiatric illness, the mean age of residents $( \pm \mathrm{SD})$ was $64 \pm 12$ years. Thirty-five percent were 70 or older. The average length of stay at the facility for the current admission was seven years. Fifty-eight percent of the residents had never been married; 36 percent were separated, widowed, or divorced; and 3 percent were married. Fifty percent of patients were admitted from a state psychiatric hospital, 5 percent from another psychiatric facility, 10 percent from an acute care hospital, 10 percent from another rest home, and 25 percent from all other settings. Seventy percent of the residents surveyed had a history of institutionalization in a psychiatric facility of some kind. Most (89 percent) had the costs of their rest home care covered by Supplemental Security Income or its equivalent; only 7 percent paid the costs themselves or were privately insured.

\section{Medication Use}

In this sample, 685 residents ( 82 percent) were taking one or more antipsychotic drugs. Of these, 106 (15 percent) were taking two antipsychotic drugs and 10 (1 percent) were taking three simultaneously. An evaluation of the means and standard deviations of dosages for these drugs revealed that their use was generally within the commonly accepted therapeutic ranges. About 10 percent of the medications were administered as needed.

Retrospective data on the use of medications were available for a mean of 35.2 months. A review of patients' records revealed that the mean number of changes in the dosage of each medication in this period was 1.1. The changes included a mean of 1.2 dosage adjustments for antipsychotic drugs, 0.6 for sedatives or hypnotics, 1.0 for antidepressants, and 1.2 for lithium. Since the initiation of a medication counted as a dosage change, these findings reflect a minimal level of adjustment in dosages.

An inspection of clinical records indicated that for all residents, an average of 3.8 notes had been made by a physician in the chart in the 12 months preceding the survey. However, records for 24.2 percent of the residents included no notes made by a physician during this period; this population included 21.7 percent of the patients receiving one antipsychotic drug and 19 percent of the patients taking two or more drugs in this class. During the same period, nurses made an average of 1.2 notes in the chart, and aides or other health care workers made an average of 9.7 notes. Some reference (very broadly construed) to the resident's mental health was found in 48 percent of the notes by physicians, 70 percent of the notes by nurses, 46 percent of the notes by aides, and 44 percent of the other notes. In the 12-month period sampled, records for 47.8 percent of all the residents studied included no notes made by physicians on any mental health issues.

\section{Clinical Measures}

No mention of tardive dyskinesia was made in the records of most of the assessed residents $(751$, or 90 percent). However, tardive dyskinesia was mentioned once in the records of 55 patients and twice in those of 17 patients. Tardive dyskinesia was mentioned three or more times in the charts of an additional 14 residents.

Among the patients taking neuroleptics, 77 percent had no clear evidence on the Abnormal Involuntary Movement Scale of any signs of tardive dyskinesia. An additional 17 percent had mild or indeterminate signs. However, surveyors found moderate or severe signs of tardive dyskinesia in 4 and 2 percent of the residents, respectively. Of the 214 residents with some movement disorders noted on examination by survey- 
ors from the Department of Health, only 36 (17 percent) had any mention of tardive dyskinesia in their records. (These assessments were made by registered nurses or social workers with considerable experience in the clinical assessment of patients receiving longterm care. However, because these surveyors did not have specific expertise in neurologic assessment, their findings should be considered approximate.)

Impairment of cognitive function was widespread. Eighty-eight percent of the surveyed patients agreed to have the Folstein Mini-Mental State Examination administered; their average score $( \pm \mathrm{SD})$ was 21.6 $( \pm 7.0)$ out of a possible score of 30 . However, 32 percent of the residents scored 20 or below - a cutoff point that generally indicates a need for the evaluation of serious cognitive impairment; 17 percent scored 15 or lower.

\section{Assessment of Staff Competency}

In response to the clinical vignette of a man admitted from a mental hospital who was taking several medications and was "making strange movements of his lips and tongue over and over again," 53 percent of the rest home staff members answered correctly that these movements could be a side effect of the antipsychotic drug he was receiving. However, nearly half the respondents failed to recognize this primary manifestation of tardive dyskinesia and instead attributed the symptoms to a stroke ( 15 percent), mental illness ( 11 percent), a heart condition ( 6 percent), or blood pressure problems (3 percent), or gave no response (12 percent).

Similar results were found when staff members were presented with the case of a resident with parkinsonian symptoms induced by haloperidol. Half the respondents correctly identified haloperidol as the potential cause, but 18 percent indicated that the likeliest cause was chlordiazepoxide (Librium), digoxin, or penicillin. An additional 13 percent indicated that a medication could not cause such effects, and 17 percent did not answer the question.

One vignette described a 69-year-old patient with chronic schizophrenia receiving several medications who was found to be disoriented and sluggish and was having trouble speaking. Asked what to do with his next dose of medication, 88 percent of the staff members tested correctly responded that the medication should be withheld until medical advice was obtained. Only 2 percent chose an incorrect response (mixing the medication dose into the patient's breakfast cereal), but 10 percent left this answer blank.

When asked the purpose of six commonly used psychoactive medications, somewhat fewer than half the respondents knew into which of four broad multiplechoice categories to place the drugs; many others provided answers that were far from accurate. For example, 22 percent indicated that the neuroleptic haloperidol (Haldol) was an antidepressant, and another 17 percent indicated that it was a minor tran- quilizer or a sedative; 14 percent did not know its purpose. Twenty-nine percent indicated that the antidepressant amitriptyline (Elavil) was an antipsychotic medication, a sedative, or a sleeping medicine, and an additional 24 percent did not know its purpose.

The neuroleptic chlorpromazine (Thorazine) was identified as an antidepressant by 12 percent and as a minor tranquilizer by 47 percent of the respondents; an additional 19 percent did not know its purpose. Another neuroleptic, trifluoperazine (Stelazine), was thought to be an antidepressant by 20 percent, a minor tranquilizer or sedative by 24 percent, and a sleeping pill by 3 percent; 13 percent did not know its purpose. The minor tranquilizer diazepam (Valium) was identified as an antipsychotic medication by 6 percent and an antidepressant by 39 percent; 15 percent did not know its purpose. Diphenhydramine hydrochloride (Benadryl) was correctly identified as a sleeping medication or sedative by 76 percent; 20 percent did not know its purpose.

When asked what effect chlorpromazine (Thorazine) has on blood pressure, 38 percent correctly indicated that the drug can lower blood pressure, which may lead to lightheadedness or fainting. However, 32 percent indicated that Thorazine has no effect on blood pressure. An additional 7 percent thought that Thorazine could raise blood pressure, and 22 percent did not offer any response to this question.

\section{Discussion}

Rest homes are a small but important part of the spectrum of long-term care. This statewide survey and the follow-up study focusing on a subset of rest homes in which residents had a high level of psychoactive-drug use raise important concerns about the characteristics of residents and the nature of care in these facilities. Although initially conceptualized as inexpensive homes offering room and board and oriented around self-care for relatively healthy residents, rest homes have increasingly come to house deinstitutionalized state-mental-hospital patients, chronically ill elderly persons, or both. Residents with histories of psychiatric institutionalization often receive psychoactive medications, particularly antipsychotic drugs, with little or no medical supervision. In addition, such residents are generally much younger than conventional rest home patients. In most states, the staff members who care for rest home residents are not required to have any training or competency in drug administration or the care of elderly or mentally ill patients.

Several conclusions emerge from this work. First, there is a very high level of psychoactive-medication use in these facilities, as well as a high proportion of residents who are deinstitutionalized, elderly, or both. At best, the high level of antipsychotic-medication use indicates the presence of a group of mentally ill patients who are receiving potent therapy with minimal professional supervision. At worst, the data raise the 
question of whether this high level of medication is truly necessary. Only careful longitudinal clinical study of patients, on and off their drug regimens, can distinguish between these two explanations and clarify the extent to which the impaired cognitive function observed in residents is a result of medication use or underlying illness.

Rest homes are not homogeneous in regard to medication use; instead, these facilities tend to cluster into homes that serve a high proportion of clients with psychiatric histories and those that cater to a more traditional geriatric clientele, although many homes do not fall into either group. The level of supervision by physicians of patients receiving neuroleptic medications in these facilities varies greatly; a sizable proportion of patients have minimal meaningful contact with a doctor or none at all for long periods. Although patients discharged from state mental health facilities are supposed to receive follow-up care at the rest home from "mental health assistants" or case workers, the frequency and intensity of such follow-up care are extremely variable. Rest home residents can be referred to outside mental health professionals for care, but this is not the rule. Nonetheless, rest home staff members' level of knowledge concerning practical patient care issues is such that they are often unable to supply the missing clinical surveillance of such patients.

These findings suggest that some rest homes may require more vigorous regulatory monitoring than they have historically received. One approach might be to designate rest homes caring for a large proportion of patients with psychiatric illness as a special type of facility within the rest home category. The administrators and staff members of such facilities would then be expected to have a somewhat higher level of expertise and ability to monitor residents, in exchange for which a higher level of reimbursement could be provided to cover the increases in the cost of care. Such specialized facilities would also alleviate the problem of mixing younger residents who have mental illness with older, conventional rest home residents, who may be frightened or troubled by the behavior of these younger residents. The Massachusetts
Department of Public Health has developed regulations that embody such an approach.

Even with the creation of a new subcategory of facility, it will still be necessary to raise the legal and regulatory expectations for care givers and managers of all rest home facilities, in order to ensure a safe base line of competence and clinical surveillance for all residents. This is particularly important because demographic changes and fiscal constraints will make such facilities more common in the coming decade. Ensuring the optimal care of these physically and psychologically vulnerable patients without creating the costs and complications of a new class of "mini-nursing homes" presents an important challenge for policy makers and care givers alike.

We are indebted to the staff of the Massachusetts Department of Public Health, Division of Health Care Quality, for assistance in the performance of the surveys, to Sharon Hawley, Harvard Medical School, for assistance with data analysis, and to Susanne Bellevance, Harvard Medical School, for assistance with the preparation of the manuscript.

\section{REFERENCES}

1. Freedman RI, Moran A. Wanderers in a promised land: the chronically mentally ill and deinstitutionalization. Med Care 1984; 22:Suppl 12: S1-S60.

2. Gudeman JE, Shore MF. Beyond deinstitutionalization: a new class of facilities for the mentally ill. N Engl J Med 1984; 311:832-6.

3. Bassuk EL, Gerson S. Deinstitutionalization and mental health services. Sci Am 1978; 238(2):46-53.

4. Shadish WR Jr, Thomas S, Bootzin R. Criteria for success in deinstitutionalization: perceptions of nursing homes by different interest groups. Am J Community Psychol 1982; 10:553-66.

5. Ray W, Federspiel CF, Schaffner W. A study of antipsychotic drug use in nursing homes: epidemiologic evidence suggesting misuse. Am J Public Health 1980; 70:485-91.

6. Beers M, Avorn J, Soumerai S, Everitt D, Sherman D, Salem S. Psychoactive medication use in intermediate-care facility residents. JAMA 1988; 260:3016-20.

7. Eckel FM, Crawley HK III. A study of pharmacy services in North Carolina rest homes. J Am Pharm Assoc 1971; 11:387-90.

8. Segal SP, Chandler S, Aviram U. Antipsychotic drugs in community-based sheltered-care homes. Soc Sci Med 1980; 14A:589-96.

9. Budden F. Adverse reactions in long-term care facility residents. J Am Geriatr Soc 1985; 33:449-50.

10. Kish L. Survey sampling. New York: John Wiley, 1965.

11. Folstein MF, Folstein SE, McHugh PR. "Mini-mental state": a practical method for grading the cognitive state of patients for the clinician. J Psychiatr Res 1975 ; 12:189-98.

12. Fann WE, Smith RC, Davis JM, Domino EF, eds. Tardive dyskinesia: research and treatment. New York: SP Medical, 1980.

\section{Massachusetts Medical Society \\ Registry on Continuing Medical Education}

To obtain information on continuing medical education courses in the New England area, write or call, indicating field(s) or specialty in which information is desired, the Committee on Medical Education, 1440 Main St., Waltham, MA 02254; telephone (617) 893-4610 (Metropolitan Boston) or WATS 1-800-322-2303 (Massachusetts). 